\title{
A method to diagnose boundary-layer type using Doppler lidar
}

Article

Accepted Version

Harvey, N. J., Hogan, R. J. and Dacre, H. F. (2013) A method to diagnose boundary-layer type using Doppler lidar. Quarterly Journal of the Royal Meteorological Society, 139 (676). pp. 1681-1693. ISSN 1477-870X doi: https://doi.org/10.1002/qj.2068 Available at https://centaur.reading.ac.uk/32179/

It is advisable to refer to the publisher's version if you intend to cite from the work. See Guidance on citing.

To link to this article DOI: http://dx.doi.org/10.1002/qj.2068

Publisher: Wiley Interscience

All outputs in CentAUR are protected by Intellectual Property Rights law, including copyright law. Copyright and IPR is retained by the creators or other copyright holders. Terms and conditions for use of this material are defined in the End User Agreement.

\section{www.reading.ac.uk/centaur}

\section{CentAUR}

Central Archive at the University of Reading 
Reading's research outputs online 


\title{
A method to diagnose boundary-layer type using Doppler lidar
}

\author{
Natalie J. Harvey, Robin J. Hogan and Helen F. Dacre \\ Department of Meteorology, University of Reading, UK \\ ${ }^{*}$ Correspondence to: Natalie J. Harvey, Department of Meteorology, The University of Reading, Earley Gate, PO Box \\ 243, Reading RG6 6BB UK. E-mail: n.j.harvey@pgr.reading.ac.uk
}

A new technique for objective classification of boundary layers is applied to ground-based vertically pointing Doppler lidar and sonic anemometer data. The observed boundary layer has been classified into nine different types based on those in the Met Office "Lock" scheme, using vertical velocity variance and skewness, along with attenuated backscatter coefficient and surface sensible heat flux. This new probabilistic method has been applied to three years of data from Chilbolton Observatory in Southern England and a climatology of boundary-layer type has been created. A clear diurnal cycle is present in all seasons. The most common boundary-layer type is stable with no cloud (30.0\% of the dataset). The most common unstable type is well mixed with no cloud (15.4\%). Decoupled stratocumulus is the third most common boundarylayer type (10.3\%) and cumulus under stratocumulus occurs $1.0 \%$ of the time. The occurrence of stable boundary-layer types is much higher in the winter than the summer and boundary-layer types capped with cumulus cloud are more prevalent in the warm seasons. The most common diurnal evolution of boundary-layer types, occurring on 52 days of our three-year dataset, is that of no cloud with the stability changing from stable to unstable during daylight hours. These results are based on 16393 hours, $62.4 \%$ of the three year dataset, of diagnosed boundary-layer type. This new method is ideally suited to longterm evaluation of boundary-layer type parameterisations in weather forecast and climate models. Copyright $(\mathbf{c} 0000$ Royal Meteorological Society

Key Words: $\quad$ stable boundary layer; decoupled boundary layer; stratocumulus 


\section{Introduction}

Boundary-layer mixing is a highly turbulent, complex and continually evolving process. One method of understanding this evolution is to classify the boundary layer, at any given time, into a reduced set of types. Observationally the boundary layer is often classified subjectively using stability and the presence of convection (e.g. Clarke 1970). These observational classifications, as well as being subjective, have previously only been applied over a short time period or on a case study basis. Examples of this include The Stable Atmospheric Boundary-Layer Experiment in Spain (SABLES 98, Cuxart et al. 2000) where two nocturnal periods were analysed, and the Cooperative AtmosphereSurface Exchange Study (CASES-99, Poulos et al. 2002) where 30 days of data were analysed.

In weather forecast and climate models boundarylayer mixing is parameterised. In order to determine which mixing scheme to apply at a given time, the boundary layer can be classified into types. This classification may be used to determine whether a local or non-local scheme is applied and whether to apply a cloud-top entrainment parameterisation, or whether to apply a shallow cumulus scheme. One such explicit classification scheme is the one currently used by the UK Met Office (Lock et al. 2000), but most other schemes contain several switches that combine to give a similar result. A long-term observational dataset of boundary-layer type would enable model parameterisations to be rigorously evaluated. It could be used to investigate the impact of cloud presence and distribution on how the state of the boundary layer can affect the transport of moisture and tracer.

Remote sensing techniques, in particular lidar, are very useful for analysing the structure of the boundary layer due to their ability to sample at many levels throughout the lower atmosphere and to record data over long time periods. As such, numerous previous studies have used ground-based and airborne lidars to diagnose boundarylayer depth (e.g. Steyn et al. 1999; Davis et al. 2000; Mok and Rudowicz 2004; Davies et al. 2007; Pearson et al. 2010; Barlow et al. 2011), determine the vertical velocity, and its higher order moments from Doppler lidar measurements (Lothon et al. 2009; Lenschow et al. 2012) and retrieve profiles of wind and temperature throughout the lower atmosphere (Newsom et al. 2005).

In this paper we demonstrate how quantities derived from a continuously operating, vertically pointing Doppler lidar, specifically the backscatter coefficient, the vertical velocity skewness and the vertical velocity variance, combined with surface flux measurements from a sonic anemometer, can be used to classify the boundary layer into types similar to those outlined in Lock et al. (2000). We then present a three-year climatological study of boundarylayer type using data from the Chilbolton Atmospheric Observatory in Southern England.

The paper is organised as follows. In Section 2 the new method of deriving boundary-layer type from Doppler lidar and sonic anemometer is described. Also in Section 2, case studies are presented to demonstrate the performance of the method for a cumulus-topped boundary layer, a stratocumulus-topped boundary layer plus a more complex case representative of a day that does not follow the textbook evolution of the boundary layer. In Section 3, the three-year study of boundary-layer types is presented before the most probable daily boundary-layer type transition sequences are discussed.

\section{Method and case studies}

The algorithm outlined in this paper classifies the boundary layer into nine types using observations from a Doppler lidar, in a vertically pointing configuration, and a sonic anemometer. The nine types diagnosed in the paper are based on the six types described in Lock et al. (2000) with their type I (stable) split into three types (Ia, Ib and Ic) and their type III (well mixed) split into two types (IIIa and IIIb), based on the presence of cloud and the number of cloud layers present. Figure 1 is a conceptual depiction of the nine boundary-layer types that we diagnose here. It summarises the stability of the surface layer, the cloud type, where turbulence is being driven from (surface or cloud top), the depth of penetration of cloud-top driven turbulence and the number of cloud layers for each boundary-layer type.

The distinction between type IIIa (well mixed) and IIIb (stratocumulus-capped) is justified since many numerical weather prediction models, including the Met Office Unified Model, effectively distinguish between them by 
applying a cloud-top entrainment scheme only when cloud is present. Types Ia and Ib are the stable analogues of types IIIa and IIIb. Type Ic (forced cumulus under stratocumulus) is a type not considered in the "Lock" scheme. It is a case where a decoupled layer of stratocumulus is present with a layer of cloud beneath. It is assumed that the lower level cloud was once surface-driven cumulus, but now the surface layer is stable. This type is most naturally grouped with type II but the "Lock" scheme would most likely treat this as type I so here it is classed as a subset of type I to facilitate model evaluation in a future paper.

The algorithm presented here uses a decision process based on several observed variables. In the remainder of this section we describe the variables required by the algorithm, present three illustrative case study days and then describe each decision in turn.

\subsection{Instrumentation and variables}

The instruments used in this paper are located at the Chilbolton Observatory in southern England $\left(51^{\circ} 09^{\prime} \mathrm{N}\right.$, $\left.01^{\circ} 26^{\prime} \mathrm{W}\right)$. The lidar used is a HALO photonics $1.5 \mu \mathrm{m}$ heterodyne Doppler lidar (Pearson et al. 2008) which records vertical profiles of attenuated backscatter coefficient, $\beta$, and Doppler velocity, $w$, once a minute and is sensitive to both cloud and aerosol. The lidar has a rangegate spacing of $36 \mathrm{~m}$.

There are many different definitions of boundary-layer depth and methods to determine it using remote sensing instruments in the literature (Endlich et al. 1979; Flamant et al. 1997; Steyn et al. 1999; Seibert et al. 2000; Davis et al. 2000; Hennemuth and Lammert 2006; Davies et al. 2007; Emeis et al. 2008). Here the boundary layer depth is determined using the attenuated backscatter coefficient. It is defined as the lowest height at which $80 \%$ of the lidar profiles within an hour have no detectable backscatter; this is similar to the gradient method for determining boundarylayer height (e.g. Flamant et al. 1997). This method has been used over other more sophisticated methods as only an hour-mean value is required. Note that as the lidar is sensitive to aerosol this definition actually estimates the aerosol depth, $h_{a e r}$. During daylight hours $h_{a e r}$ and other measures of boundary-layer height can be equivalent but during the night $h_{a e r}$ gives a depth more representative of the residual layer rather than a measure of the depth of the stable boundary layer. Also, the lidar beam is rapidly attenuated by cloud, so in the presence of thick cloud $h_{a e r}$ will be lower than the cloud top.

The Doppler velocity $w$ can be used to calculate both the vertical velocity variance,

$$
\sigma_{w}^{2}=\overline{w^{\prime 2}}
$$

and the vertical velocity skewness,

$$
s=\frac{\overline{w^{\prime 3}}}{{\overline{w^{\prime 2}}}^{3 / 2}} .
$$

Here the overbars denote both time and spatial means. Time means are two-hour averages centered on the hour of interest, calculated hourly. Spatial means are calculated over each set of three adjacent range gates (covering $108 \mathrm{~m}$ ). These choices were made to increase the sample sizes for each observation whilst retaining sufficient temporal and spatial resolution. Together these quantities are used to determine both the cloud type, cumulus or stratocumulus, and also whether any cloud layers are decoupled from the surface. One use of the climatology produced by this algorithm will be to provide an observation-based data set that can be used to evaluate numerical weather prediction and climate models, and therefore the boundary-layer types diagnosed relate to the underlying physics that is affecting the boundary layer such as the turbulent kinetic energy budget or turbulent transport. This makes a skewness-based approach to the cumulus/stratocumulus distinction more attractive than just using a cloud fraction threshold.

The sonic anemometer used in this study is mounted at a height of $5 \mathrm{~m}$ above the ground and measures the three components of the wind and the sonic temperature at a rate of $20 \mathrm{~Hz}$. Standard eddy-correlation techniques are used to estimate the hourly mean sensible heat flux, $H=\rho C_{\mathrm{p}} \overline{w^{\prime} T^{\prime}}$, where $\rho$ is the density of air, $C_{\mathrm{p}}$ is the specific heat capacity of dry air, $w^{\prime}$ is the fluctuation of the vertical velocity from its detrended hourly-mean value and $T^{\prime}$ is the fluctuation of the sonic temperature (equivalent to the virtual temperature, not true air temperature) from its detrended hourly-mean value. The hourly-mean sensible heat flux is used to determine the stability of the surface 
(a)

la. Stable boundary layer, no cloud (Stable)

no cloud

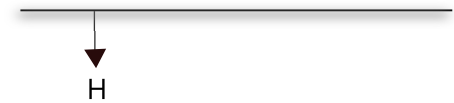

(d)

II. Decoupled stratocumulus over a stable

surface layer (Stable u. Sc)

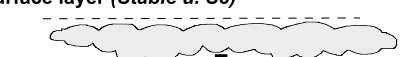

$\uparrow \uparrow \longdiv { \uparrow }$ turbulent

non-turbulent

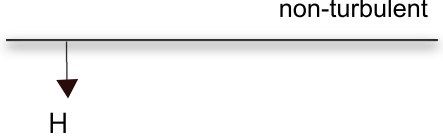

(g)

IV. Decoupled stratocumulus

(Dec. Sc)

$\uparrow \uparrow \downarrow \uparrow 1$

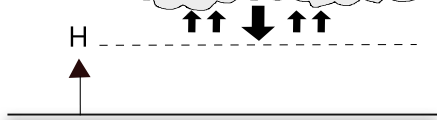

(b)

lb. Stratus topped stable boundary layer, no cumulus (Stable St)

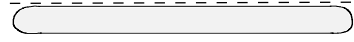

non-turbulent

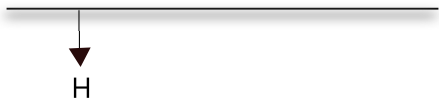

(e)

IIla. Single mixed layer, no cloud (Well mixed)

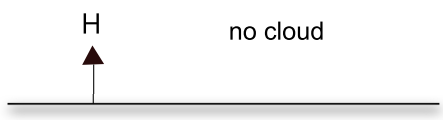

(h)

v. Decoupled stratocumulus over cumulus

(Cu u. Sc)

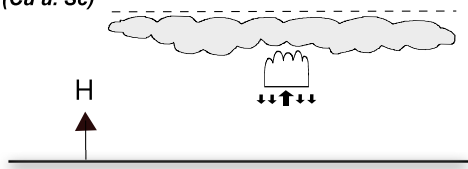

(c)

Forced cumulus under stratocumulus (Forced Cu u. Sc)

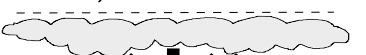

$\uparrow \uparrow \widehat{1} \uparrow$ turbulent

non-turbulent

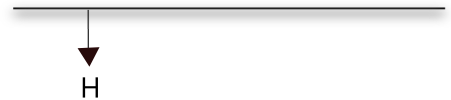

(f)

IIlb. Single stratocumulus-topped mixed layer, no cumulus (Sc)

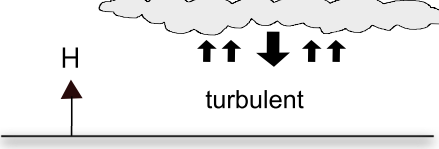

(i)

Vumulus capped layer

(Cu)

Figure 1. Conceptual representation of the nine boundary-layer types. The upper dashed line indicates the top of the aerosol layer. The direction of the large thick black arrow indicates whether the cloud-base turbulence is being driven from either the surface (upward-pointing arrow) leading to positive vertical-velocity skewness or cloud top (downward-pointing arrow) leading to negative skewness. The lower dashed lines represent the depth to which turbulence driven by cloud top cooling reaches (for types II and IV only). The direction of the narrow arrow labelled $H$ indicates the sign of the sensible heat flux and the stability of the surface layer. The text in brackets are shortened descriptions of the boundary-layer types used in later figures and tables.

Table I. Definition of probabilities calculated by the algorithm and the variable each probability is based on.

\begin{tabular}{|c|c|c|}
\hline Probability & Variable & Description \\
\hline$p_{\mathrm{c}}$ & $\beta$ & probability of the presence of boundary-layer cloud ( 0 or 1$)$ \\
\hline$p_{\text {st }}$ & $\bar{H}$ & probability of the surface layer being stable $(\bar{H}<0)$ \\
\hline$p_{\text {sk }}$ & $s$ & $\begin{array}{l}\text { probability of mixing driven by cloud top-cooling being present in the top third } \\
\text { of the boundary layer }(s ; 0)\end{array}$ \\
\hline$p_{\text {var }}$ & $\sigma_{w}^{2}$ & $\begin{array}{l}\text { probability of significant turbulence being present in the top third of the } \\
\text { boundary layer }\left(\sigma_{w}^{2}>0.1 \mathrm{~m}^{2} \mathrm{~s}^{-2}\right)\end{array}$ \\
\hline$p_{\mathrm{de}}$ & $\sigma_{w}^{2}$ & probability of the cloud layer being decoupled \\
\hline$p_{\text {2lay }}$ & $\beta$ & probability of two cloud layers being present \\
\hline
\end{tabular}

layer. It should be noted that in principle this method would work with any Doppler lidar and sonic anemometer.

\subsection{Probability calculation}

In practice, each of these quantities are calculated from finite samples of data and therefore have associated sampling uncertainties. As a result, the algorithm presented here is probabilistic; for each hour of observational data a probability is assigned to each boundary-layer type rather than deterministically producing the most likely type. Figure 2 shows the decision path taken to diagnose each boundary-layer type, and the probabilities outlined in Table I. Table I also shows the observed variable that each probability is based on. The use of this probabilistic approach gives information on the significance of the most likely type diagnosed, and in particular highlights when there is uncertainty in the type diagnosed. In addition it reduces the dependence of our results on arbitrary thresholds, although it does not eliminate them. If the number of independent samples of a particular variable $X$ is large enough then, using the central limit theorem, the probability of the mean value of $\mathrm{X}$ being less than a threshold value, $\chi$ is given by the normal cumulative distribution function

$$
p_{X}=0.5\left[1+\operatorname{erf}\left(\frac{z}{\sqrt{2}}\right)\right] \text {, }
$$


Table II. How the probabilities are combined to give overall boundarylayer type probability, where the probabilities are defined in Table I.

\begin{tabular}{ll}
\hline Boundary-Layer Type & Probability \\
\hline Ia Stable & $\left(1-p_{c}\right) p_{\text {st }}$ \\
Ib Stable Sc & $p_{c} p_{\text {st }}\left(1-p_{\text {sk }} p_{\text {var }}\right)$ \\
Ic Forced Cu u. Sc & $p_{c} p_{\text {st }} p_{\text {sk }} p_{\text {var }} p_{2 \text { lay }}$ \\
II Stable u. Sc & $p_{c} p_{\text {st }} p_{\text {sk }} p_{\text {var }}\left(1-p_{2 l a y}\right)$ \\
IIIa Well mixed & $\left(1-p_{c}\right)\left(1-p_{\text {st }}\right)$ \\
IIIb Sc & $p_{c}\left(1-p_{\text {st }} p_{\text {sk }}\right)\left[1-p_{\text {var }}\left(1-p_{\text {de }}\right)\right]$ \\
IV Dec Sc & $p_{c}\left(1-p_{\text {st }}\right) p_{\text {sk }} p_{\text {var }}\left(1-p_{\text {de }}\right)$ \\
V Cu u. Sc & $p_{c}\left(1-p_{\text {st }}\right)\left(1-p_{\text {sk }}\right) p_{2 \text { lay }}$ \\
VI Cu & $p_{c}\left(1-p_{\text {st }}\right)\left(1-p_{\text {sk }}\right)\left(1-p_{2 l a y}\right)$ \\
\hline
\end{tabular}

where

$$
z=\frac{\chi-\bar{X}}{\Delta \bar{X}}
$$

It is assumed that the probability determined at each decision is independent of all other decisions. Table II shows how, based on Figure 2, the probabilities are multiplied to give the overall probability for each boundary-layer type for each hour. For example the probability of the boundary layer being type $\mathrm{V}$ (decoupled stratocumulus over cumulus) is $p_{c} \times\left(1-p_{\mathrm{st}}\right) \times(1-$ $\left.p_{\text {sk }}\right) \times p_{\text {2lay }}$ (probabilities defined in Table I). Note that not all decisions are needed to determine each boundary-layer type. For example, if there is no cloud present $\left(p_{\mathrm{c}}=0\right)$ then the only possible types are Ia (Stable) and IIIa (Well mixed).

\subsection{Case studies}

Here three case study days are presented. These are included to give confidence in the inferences from the observations and to aid the description of the method.

\subsubsection{Cumulus-topped boundary layer}

Figure 3 shows the observations for a shallow cumuluscapped layer on 11 September 2009. The difference between the stable and unstable periods can be seen in all variables. The growth of the convective boundary layer throughout the morning is evident in both the backscatter and the standard deviation of the vertical velocity. Just after midday the turbulence driven by surface heating is associated with a skewness value of 1 (panel b) and a maximum vertical velocity standard deviation greater than $1 \mathrm{~ms}^{-1}$ (panel c). The sensible heat flux peak is approximately $200 \mathrm{Wm}^{-2}$ (panel d). In this case the clear sky stable boundary-layer type Ia is diagnosed until the sensible heat flux changes sign at 0800 UTC after which unstable types are diagnosed. Cloud appears at 0900 UTC and caps the boundary layer throughout its development until it disperses at 1800 UTC, although the boundary-layer type diagnosed is not cumulus (VI) until 1300 UTC due to the fraction of the hour that is cloudy being less than the threshold required by the algorithm (5\%). The sensible heat flux changes back to negative values at 1800 UTC from which point boundary-layer type Ia is diagnosed indicating a stable surface layer and clear-sky conditions. Examples of raw vertical velocity measurements from similar days can be found in Hogan et al. (2009). Table III shows the probability of each boundary-layer type for each hour on this day as derived by the algorithm. The most probable type is shaded in grey. In this straightforward case the most probable boundary-layer type has a probability of greater than $87 \%$ for all hours.

\subsubsection{Stratocumulus-topped boundary layer}

Next we consider a case where stratocumulus breaks up during the day to give a cumulus-capped boundary layer. Figure 4 shows the observational data as in Figure 3 but from 18 October 2009. Turbulence driven by cloudtop cooling occurs between 0600 and 1000 UTC. This turbulence has a peak of vertical velocity standard deviation, $\sigma_{w}$, of approximately $0.5 \mathrm{~ms}^{-1}$ and does not extend to the surface. This is similar to the signature of decoupled stratocumulus cloud observed by Hogan et al. (2009). At 1100 UTC the turbulence driven from the cloud base reaches the surface and the cloud is no longer decoupled from the surface. Increased surface heating gives rise to an increase in surface-driven turbulence with a peak $\sigma_{w}$ of approximately $0.8 \mathrm{~ms}^{-1}$ and positive vertical velocity skewness throughout the depth of the boundary layer until 1500 UTC when the sensible heat flux changes sign and the surface layer becomes stable. As expected this stability persists until the end of the day with cloudy boundarylayer types diagnosed. This cloud layer becomes decoupled from 1700 UTC onwards due to turbulence generated by cloud-top cooling. In this more complex case there are four hours in which the most probable boundary-layer type has a probability of less than $60 \%$ (Table IV). 


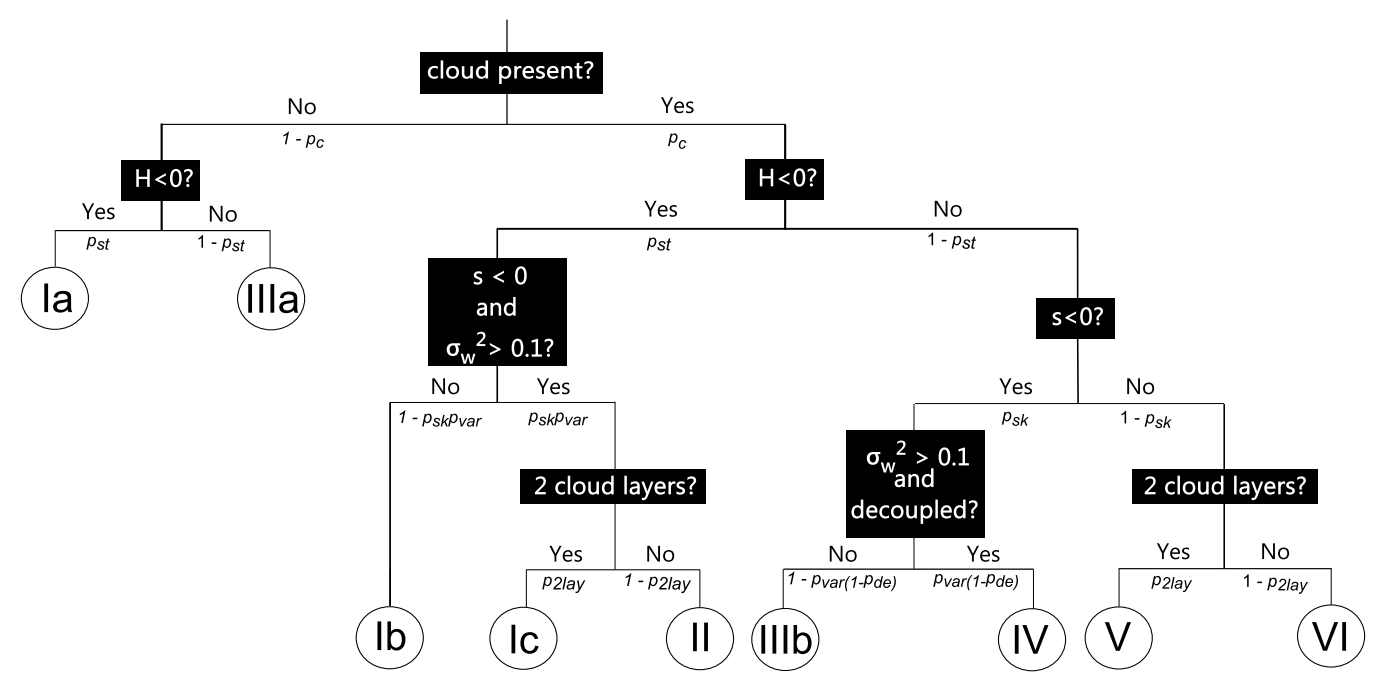

Figure 2. A schematic diagram illustrating the decisions made for each boundary-layer type depicted in 1 (clear circles) and its associated probability as described in Table I.

\subsubsection{A more complex day}

Figure 5 shows the same as Figure 3 but for 4 July 2009. This case has been included as it is an example of a more complex day when the "textbook" boundary layer evolution is not as evident. It also includes boundary-layer type $\mathrm{V}$ (cumulus under stratocumulus) at 1000 and 1200 UTC, when more than one cloud layer is observed. At 1200 UTC positive vertical velocity skewness can be seen up to a height of approximately $500 \mathrm{~m}$ beneath a cloud layer which is indicative of cumulus cloud; however, above the cloud at $1 \mathrm{~km}$ there is a shallow layer, approximately $200 \mathrm{~m}$ thick, of negative vertical velocity skewness beneath another cloud layer which is indicative of stratocumulus cloud, hence the diagnosis of cumulus under decoupled stratocumulus. This boundary-layer type is common over the ocean (Norris 1998), but there have been no long term studies of this boundary-layer type over land to evaluate its frequency. In this case there are three hours in which the most probable boundary-layer type has a probability of less than $50 \%$ (Table V). Note that no boundary-layer type was diagnosed at 0300 or 0400 UTC as the cloud base is below the first range gate of the lidar during those times and therefore there was no skewness or variance information to base the diagnosis on.

\subsection{The algorithm in detail}

Here we discuss and justify each decision in the algorithm as shown in Figure 2.

\subsubsection{Presence of cloud}

All clouds below $h_{a e r}$ are considered, by our definition, to be in the boundary layer and are therefore included in the diagnosis of the boundary-layer type. It is important to reiterate that $h_{a e r}$ is actually a measure of the aerosol depth and is not necessarily equal to other measures of the boundary layer height in the literature. Cloud is considered to be present during a given hour if a cloud is detected for more than $5 \%$ of the hour-long window. The value of $5 \%$ was chosen as it is comparable to the cloud fraction of small cumulus clouds that we wish to detect. The sensitivity to this threshold has been tested and Table VI shows the percentage of cloudy and non-cloudy boundary-layer types diagnosed for a range of threshold values. When the threshold is increased to $10 \%$ approximately $3 \%$ of the boundary-layer types diagnosed change from cloudy to non-cloudy. If the threshold is removed completely approximately $4 \%$ of the types move from cloud-free to cloudy. The backscatter threshold used to identify cloud is $5 \times 10^{-5} \mathrm{~m}^{-1} \mathrm{sr}^{-1}$. This threshold is consistent with that used in other studies such as Hogan et al. (2004) and Westbrook et al. (2010). Note that $p_{c}$ can only have a value of 0 or 1 as it is the presence of cloud that is being determined, not the fraction of time a cloud is present. No error on cloud presence is determined as the difference in backscatter attenuation coefficient between cloud and aerosol is very large and therefore the error in detecting a cloud with the lidar is very small.

Q. J. R. Meteorol. Soc. 00: 2-15 (0000) 
(a)
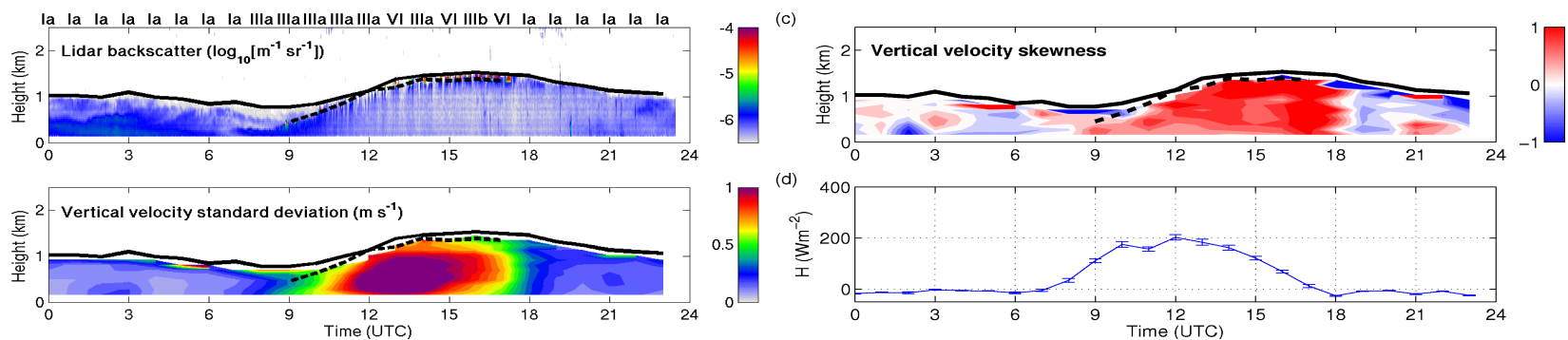

Figure 3. Observations taken on 11 September 2009: (a) attenuated lidar backscatter coefficient with the most probable boundary-layer type shown in Roman numerals, (b) 2-hourly mean skewness of vertical velocity, (c) 2-hourly mean standard deviation of vertical velocity, (d) hourly-mean surface sensible heat flux. In (a), (b) and (c) the solid black indicates the diagnosed boundary-layer and the dashed lines indicate the diagnosed cloud bases .

Table III. The probability of each boundary-layer type for each hour of 11 September 2009. Grey shading indicates the most probable type.

\begin{tabular}{|c|c|c|c|c|c|c|c|c|c|c|c|c|c|c|c|c|c|c|c|c|c|c|c|c|c|}
\hline Time & & 0 & 1 & 2 & 3 & 4 & 5 & 6 & 7 & 8 & 9 & 10 & II & 12 & 13 & 14 & 15 & 16 & 17 & 18 & 19 & 20 & 21 & 22 & 23 \\
\hline Ta & Stable & 1 & 1 & 1 & 0.919 & 1 & 1 & 1 & 0.875 & 0 & 0 & 0 & 0 & 0 & 0 & 0 & 0 & 0 & 0 & 1 & 1 & 1 & 1 & 1 & 1 \\
\hline $\mathrm{Ib}$ & $\begin{array}{l}\text { Stable St } \\
\text { Forced }{ }^{2}\end{array}$ & $\begin{array}{l}0 \\
0\end{array}$ & $\begin{array}{l}0 \\
0 \\
0\end{array}$ & $\begin{array}{l}0 \\
0 \\
0\end{array}$ & $\begin{array}{l}0 \\
0 \\
0\end{array}$ & $\begin{array}{l}0 \\
0 \\
0\end{array}$ & 0 & 0 & $\begin{array}{l}0 \\
0\end{array}$ & 0 & 0 & 0 & 0 & 0 & 0 & 0 & 0 & 0 & 0.032 & 0 & 0 & 0 & 0 & 0 & 0 \\
\hline II & Stable u. Sc & 0 & 0 & 0 & $\begin{array}{l}0 \\
0\end{array}$ & 0 & 0 & 0 & 0 & 0 & 0 & 0 & 0 & 0 & 0 & 0 & 0 & 0 & $\begin{array}{l}0 \\
0\end{array}$ & 0 & 0 & 0 & 0 & 0 & 0 \\
\hline IIIIa & Well mixed & 0 & 0 & 0 & 0.081 & 0 & 0 & 0 & 0.125 & 1 & 1 & 1 & 1 & 1 & & 1 & 0 & 0 & 0 & 0 & 0 & 0 & 0 & 0 & 0 \\
\hline IIIlb & & 0 & 0 & 0 & 0 & 0 & 0 & 0 & 0 & 0 & 0 & 0 & 0 & 0 & 0.094 & 0 & 0.119 & 1 & 0 & 0 & 0 & 0 & 0 & 0 & 0 \\
\hline IV & $\operatorname{Dec} \mathbf{S c}$ & 0 & 0 & 0 & 0 & 0 & 0 & 0 & 0 & 0 & 0 & 0 & 0 & 0 & & 0 & 0 & 0 & 0 & 0 & 0 & 0 & 0 & 0 & 0 \\
\hline $\mathrm{V}$ & $\mathrm{Cu}$ u. Sc & 0 & 0 & 0 & 0 & 0 & 0 & 0 & 0 & 0 & 0 & 0 & 0 & 0 & & 0 & 0 & 0 & 0 & 0 & 0 & 0 & 0 & 0 & 0 \\
\hline VI & $\mathrm{Cu}$ & 0 & 0 & 0 & 0 & 0 & 0 & 0 & 0 & 0 & 0 & 0 & 0 & 0 & 0.960 & 0 & 0.881 & 0 & 0.968 & 0 & 0 & 0 & 0 & 0 & 0 \\
\hline
\end{tabular}

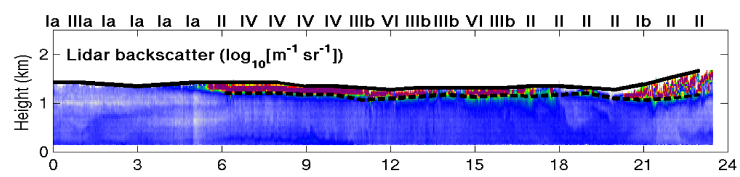

(b)

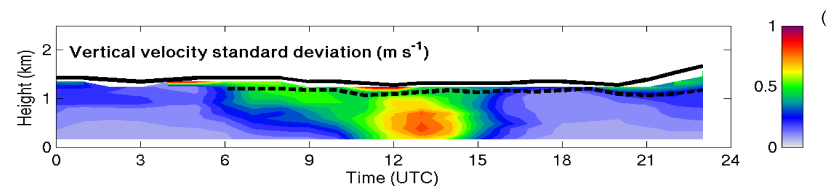

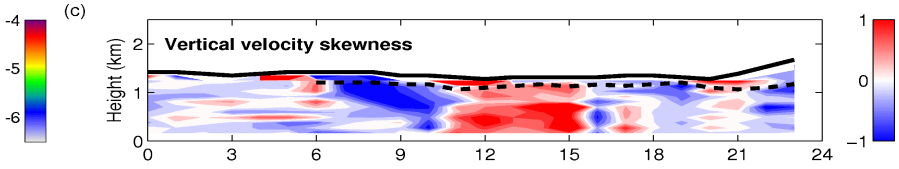

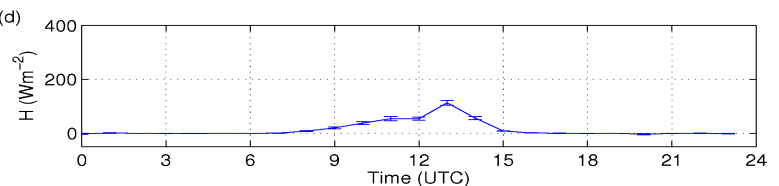

Figure 4. As Figure 3, but for 18 October 2009.

Table IV. As Table III but for 18 October 2009.

\begin{tabular}{|c|c|c|c|c|c|c|c|c|c|c|c|c|c|c|c|c|c|c|c|c|c|c|c|c|c|}
\hline Time & & 0 & 1 & 2 & 3 & 4 & 5 & 6 & 7 & 8 & 9 & 10 & $\pi$ & 12 & 13 & 14 & 15 & 16 & 17 & 18 & 19 & 20 & 21 & 22 & 23 \\
\hline Ta & Stable & 0.992 & 0.096 & 0.860 & 0.959 & 0.917 & 1 & 0 & 0 & 0 & 0 & 0 & 0 & 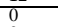 & 0 & 0 & 0 & & & & & & & & \\
\hline $\mathrm{Ib}$ & Stable St & 0 & 0 & 0 & 0 & 0 & 0 & 0.001 & 0 & 0 & 0 & 0 & 0 & 0 & 0 & 0 & 0 & 0.009 & 0.060 & 0.111 & 0.121 & 0.272 & 0.625 & 0.014 & 0.007 \\
\hline II & Forced $\mathrm{Cu}$ u. Sc & 0 & 0 & $\begin{array}{l}0 \\
0\end{array}$ & 0 & 0 & 0 & 0 & 0 & 0 & 0 & 0 & 0 & 0 & 0 & 0 & 0 & ${ }_{0}^{0} 030$ & 0 & $\begin{array}{l}0 \\
0781\end{array}$ & & 0 & 0 & 0 & 0 \\
\hline IIIIa & $\begin{array}{l}\text { Stable u. Sc } \\
\text { Well mixed }\end{array}$ & 0.008 & 0.904 & 0.140 & 0.041 & 0.083 & 0 & $\begin{array}{l}0.982 \\
0\end{array}$ & $\begin{array}{l}0.104 \\
0\end{array}$ & o & 0 & $\begin{array}{l}0 \\
0 \\
0\end{array}$ & & 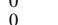 & & 0 & 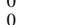 & 0 & & $\begin{array}{l}0.181 \\
0\end{array}$ & & $\begin{array}{l}0.6 / 2 \\
0\end{array}$ & $\begin{array}{l}0.359 \\
0\end{array}$ & $\begin{array}{l}0.532 \\
0\end{array}$ & 0.938 \\
\hline IIIb & & 0 & & & 0 & 0 & 0 & 0 & & 0.014 & 0.018 & 0.046 & 0.942 & 0.091 & 0.862 & 0.875 & 0.400 & 0.662 & 0.129 & 0.081 & 0.158 & 0.001 & & & 0 \\
\hline IV & Dec Sc & 0 & 0 & 0 & 0 & 0 & 0 & 0.017 & 0.896 & 0.986 & 0.982 & 0.921 & 0.011 & $0.071^{1}$ & 0.016 & & 0.030 & 0.289 & 0.246 & 0.025 & 0.160 & 0.039 & 0.006 & 0.423 & 0.055 \\
\hline v & $\mathrm{Cu} u$ & 0 & 0 & 0 & 0 & 0 & 0 & 0 & 0 & 0 & 0 & & 0 & 0 & & & & 0 & & 0 & & & & & 0 \\
\hline VI & $\mathrm{Cu}$ & 0 & 0 & 0 & 0 & 0 & 0 & 0 & 0 & 0 & 0 & 0.033 & 0.047 & 0.838 & 0.122 & 0.125 & 0.570 & 0.010 & 0.010 & 0.002 & 0.001 & 0.016 & 0.010 & 0.011 & 0 \\
\hline
\end{tabular}

(a)

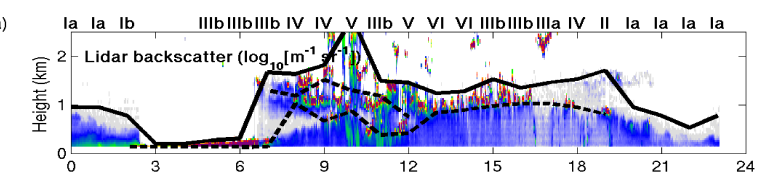

(b)

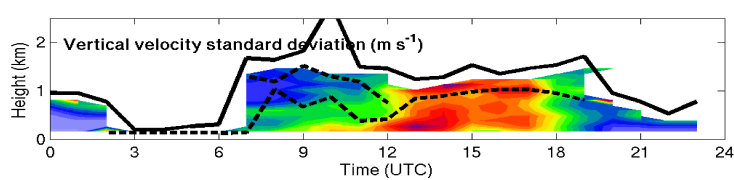

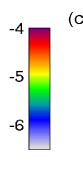
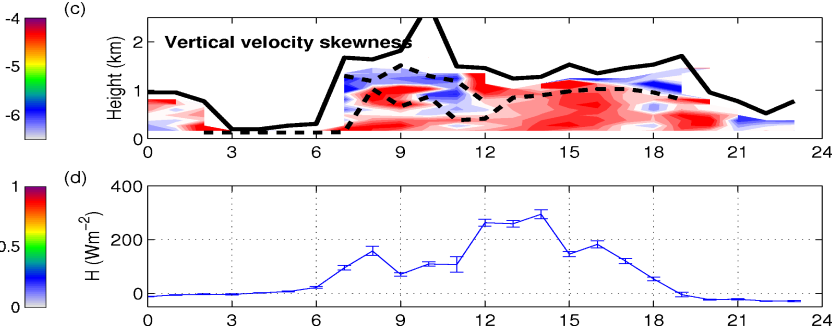

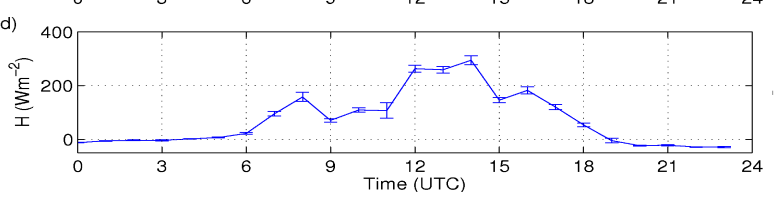

Figure 5. As Figure 3, but for 4 July 2009.

Table V. As Table III but for 4 July 2009.

\begin{tabular}{|c|c|c|c|c|c|c|c|c|c|c|c|c|c|c|c|c|c|c|c|c|c|c|c|c|}
\hline Time & & $\pi$ & $\mathrm{T}$ & 2 & 3 & 5 & 6 & 7 & 8 & 9 & T0 & TII & 12 & 13 & 14 & 15 & 16 & 17 & 18 & 19 & 20 & 21 & 22 & 23 \\
\hline Ta & Stable & 1 & 1 & 0 & & 0 & 0 & 0 & 0 & 0 & 0 & 0 & 0 & 0 & 0 & 0 & 0 & 0 & 0 & & 1 & 1 & 1 & 1 \\
\hline $\mathrm{Ib}$ & Stable St & 0 & 0 & 0.985 & & 0 & 0 & 0 & 0 & 0 & 0 & 0 & 0 & 0 & 0 & 0 & 0 & 0 & 0 & 0.243 & 0 & 0 & 0 & 0 \\
\hline Ic & Forced $\mathrm{Cu}$ u. Sc & 0 & 0 & 0 & & 0 & 0 & 0 & 0 & 0 & 0 & 0 & 0 & 0 & 0 & 0 & 0 & 0 & 0 & & 0 & 0 & 0 & 0 \\
\hline II & Stable u. Sc & 0 & 0 & 0 & & 0 & 0 & 0 & 0 & 0 & 0 & 0 & 0 & 0 & 0 & 0 & 0 & 0 & 0 & 0.475 & 0 & 0 & 0 & 0 \\
\hline IIIIa & Well mixed & 0 & 0 & 0 & & 0 & 0 & 0 & & 0 & 0 & 0 & & & 0 & & 0 & 1 & & & 0 & 0 & 0 & 0 \\
\hline IIIb & Sc & 0 & 0 & 0.015 & & 1 & 1 & 1 & 0.366 & 0.003 & 0 & 0.499 & 0.001 & 0.009 & 0.155 & 0.987 & 0.941 & 0 & 0.011 & 0.119 & 0 & 0 & 0 & 0 \\
\hline IV & Dec Sc & 0 & 0 & 0 & & 0 & 0 & 0 & 0.488 & 0.906 & 0 & 0.479 & 0.001 & 0.256 & 0.058 & 0.013 & 0.059 & 0 & 0.989 & 0.068 & 0 & 0 & 0 & 0 \\
\hline V & Cu u. Sc & 0 & 0 & 0 & & 0 & 0 & 0 & 0.097 & 0.091 & 1 & 0.004 & 0.665 & & & 0 & 0 & 0 & 0 & & 0 & 0 & 0 & 0 \\
\hline VI & $\mathrm{Cu}$ & 0 & 0 & 0 & & 0 & 0 & 0 & 0.049 & 0 & 0 & 0 & 0.333 & 0.735 & 0.787 & 0 & 0 & 0 & 0 & 0.095 & 0 & 0 & 0 & 0 \\
\hline
\end{tabular}


Table VI. Cloud fraction threshold sensitivity analysis

\begin{tabular}{ccc}
\hline $\begin{array}{c}\text { Cloud } \\
\text { fraction } \\
\text { threshold }(\%)\end{array}$ & $\begin{array}{c}\text { Cloudy types } \\
(\%)\end{array}$ & $\begin{array}{c}\text { Non-cloudy } \\
\text { types }(\%)\end{array}$ \\
\hline 0 & 58.21 & 41.79 \\
5 & 54.91 & 45.09 \\
10 & 52.03 & 47.97 \\
20 & 47.73 & 52.27 \\
50 & 37.48 & 62.52 \\
\hline
\end{tabular}

\subsubsection{Stability}

The stability of the surface layer is determined using the sign of the sensible heat flux, $H$. The probability of $H$ being negative, i.e. the surface layer being stable, $p_{s t}$, is found by calculating the sampling error of $H$ using an autocorrelation method (Wilks 1995) as follows.

The autocorrelation function is defined as

$$
R(\tau)=\frac{1}{N \sigma_{H}^{2}} \sum_{t} H(t) H(t+\tau),
$$

where $N$ is the number of samples of $H$ in 1 hour and $\tau$ is a time lag (Kaimal and Finnigan 1994). The time to independence or integral time scale, $\tau_{\text {ind }}$, of the autocorrelation function is then defined as

$$
\tau_{\text {ind }}=\int_{0}^{\tau^{*}} R(\tau) \mathrm{d} \tau
$$

where $\tau^{*}$ is the smallest lag time such that $R(\tau)=0$. Equation (6) is used to calculate the effective number of independent samples, $N_{i}$, in the hour using the expression

$$
N_{i}=\frac{N \tau_{0}}{2 \tau_{\text {ind }}}
$$

where $\tau_{0}$ is the time between each sample, equal to $0.05 \mathrm{~s}$ for our instrument. The standard error of the hourly mean sensible heat flux measurement, $\Delta \bar{H}$, is then determined using

$$
\Delta \bar{H}=\frac{\sigma_{H}}{\sqrt{N_{\mathrm{i}}}}
$$

where $\sigma_{H}$ denotes the standard deviation of the $H$ measurements over the hour.

Due to the large number of independent samples, typically around 600, Equations 3 and 4 can be used to calculate the probability, $p_{s t}$, of a negative hourly-mean value of sensible flux with $X$ replaced with $H$ and threshold value $\chi$ taken to be zero. Note that the probability of the surface layer being stable derived here is not sensitive to our choice of sonic temperature over true temperature.

\subsubsection{Cloud type}

The distinction between stratocumulus and cumulus is needed to distinguish between unstable types IIIb (Sc), IV (Dec Sc), V ( $\mathrm{Cu}$ u. Sc) and VI $(\mathrm{Cu})$, and stable types Ib (Stable St), Ic (Forced $\mathrm{Cu}$ u. Sc) and II (Stable u. Sc). The sign of the minimum of the vertical velocity skewness (see (2)), in the top third of the boundary layer indicates whether stratocumulus or cumulus cloud is present if it is assumed that in stratocumulus cloud turbulence is mostly driven from above the cloud through cloud-top cooling (negative skewness) and the turbulence associated with cumulus cloud is driven from the surface (positive skewness) (LeMone 1990; Moeng and Rotunno 1990; Moyer and Young 1991; Lothon et al. 2009; Hogan et al. 2009).

An example of the difference between cumulus and stratocumulus skewness profiles is illustrated in Figure 4(c). Negative skewness can be seen in the top third of the boundary layer from 0600 UTC to 1000 UTC implying the dominance of turbulence driven by cloud top cooling and the presence of stratocumulus cloud. However, from 1100 UTC positive skewness can be seen, implying that surface driven turbulence becomes dominant and therefore the presence of cumulus cloud. Note that if the boundary layer is diagnosed as stable and two layers of cloud are present then only the skewness between the cloud layers is considered, as it is the type of the upper-level cloud that is of interest.

The probability of the minimum skewness in the top third of the boundary layer being negative, $p_{s k}$, is calculated using an autocorrelation method analogous to that described in Section 2.4.2. The standard error in the sample skewness, $\Delta \mathrm{s}$, is given by

$$
\Delta s=\sqrt{\frac{6}{N_{i}}}
$$

(Tabachnick and Fidell 1989). As before, it is assumed that the distribution is Gaussian, with $N_{i}$ in this case being 
Table VII. Variance threshold sensitivity analysis

\begin{tabular}{ccc}
\hline $\begin{array}{c}\text { Variance } \\
\text { threshold } \\
\left(\mathrm{m}^{2} \mathrm{~s}^{-2}\right)\end{array}$ & $\begin{array}{c}\text { Types Ic and } \\
\text { II }(\%)\end{array}$ & Type IV (\%) \\
\hline 0.05 & 18.62 & 8.37 \\
0.1 & 17.65 & 8.85 \\
0.2 & 14.09 & 7.87 \\
0.3 & 11.08 & 6.83 \\
\hline
\end{tabular}

approximately 60 . The same method used to determine $p_{s t}$ in Equations 3 and 4 is also used to calculate $p_{s k}$.

The vertical velocity variance is also used to determine cloud type as it is a proxy for the presence of turbulence. For cloud to be considered as stratocumulus rather than stratus, a significant amount of turbulence driven by cloudtop cooling by outgoing long-wave radiation is needed within and possibly below the cloud depending on the thickness of the cloud layer. The distinction between stratus and stratocumulus is important as stratus cloud will have no influence on the aerosol layer beneath but may have a similar skewness and backscatter profile. In this method a significant level of turbulence is defined as having maximum vertical velocity variance greater than $0.1 \mathrm{~m}^{2} \mathrm{~s}^{-2}$, as observed by Albrecht et al. (1995), in the top third of the boundary layer or at the top of the first cloud layer. Sensitivity tests have been performed on this threshold value. The results of these are shown in Table VII. Reducing the threshold to $0.05 \mathrm{~m}^{2} \mathrm{~s}^{-2}$ only changes the percentage of cases where stratocumulus cloud is diagnosed from $8.85 \%$ to $8.37 \%$. A larger impact is seen when threshold was increased to $0.2 \mathrm{~m}^{2} \mathrm{~s}^{-2}$ especially in the cases where the surface layer is stable.

The calculation of $p_{v a r}$ is the same as that for $p_{s k}$ except the standard error in variance measurements, $\Delta \overline{w^{\prime 2}}$, is given by

$$
\Delta \overline{w^{\prime 2}}=\sigma_{w}^{2} \times \sqrt{\frac{2}{N_{i}-1}},
$$

(Spiegel and Stephens 1998) and the threshold value in (4), $\chi$, is set to $0.1 \mathrm{~m}^{2} \mathrm{~s}^{-2}$.

\subsubsection{Decoupled stratocumulus}

Figure 4 shows a case study day where the cloud layer evolves from decoupled to coupled. At 0900 UTC there is a layer of cloud diagnosed as stratocumulus due to negative skewness in the top third of the boundary layer and vertical velocity variance greater than $0.1 \mathrm{~m}^{2} \mathrm{~s}^{-2}$ in the top third of the boundary layer. It is trivial to diagnose the layer as decoupled by eye as the turbulence below the cloud base does not reach the surface or the top of any turbulence driven by surface heating. At 1500 UTC on the same day the cloud layer still persists but the surface-driven turbulence reaches up to cloud base and thus the boundary layer is coupled. Again, by eye this diagnosis is trivial. However, in practice, implementing this decision as an objective algorithm is non-trivial.

One method of determining whether the cloud layer is decoupled is by considering the profiles of vertical velocity variance. In the case where the cloud layer is coupled with the surface we would expect the vertical variance profile to have a maximum in the bottom half of the boundary layer. Associated with this we would expect a convex variance profile, i.e. the variance profile to have a gradient that decreases with height in the lower half of the boundary layer (Lenschow et al. 1980; Sorbjan 1989). On the contrary, if a layer is decoupled then we expect a maximum in the vertical velocity variance profile in the top half of the boundary layer which in turn will give a gradient that increases with height in the lower half of the boundary layer. These differences can be seen in Figure 6 (panels (a) and (c)) which shows the vertical profiles of two-hour mean vertical velocity variance for 0900 UTC and 1400 UTC on the 18 October 2009. It is possible to classify the shape of the variance profile using its second derivative as this describes the change of gradient with height. As the vertical profiles of variance are noisy, we cannot simply use the numerical second derivative of the raw measurements so a quartic function is fitted to the observed profile and the second derivative of this quartic is used. This fit is shown in Figure 6 by a dashed line. Figure 6 panel (b) shows a decoupled case. The second derivative is positive at all but one range gate in the bottom half of the boundary layer and therefore the boundary layer is diagnosed as decoupled. Figure 6 panel (d) shows the same plot but in this case the second derivative is negative in the bottom half of the boundary layer and thus the boundary layer is diagnosed as coupled.

The probability of this second derivative being negative is calculated at the height of maximum curvature of 

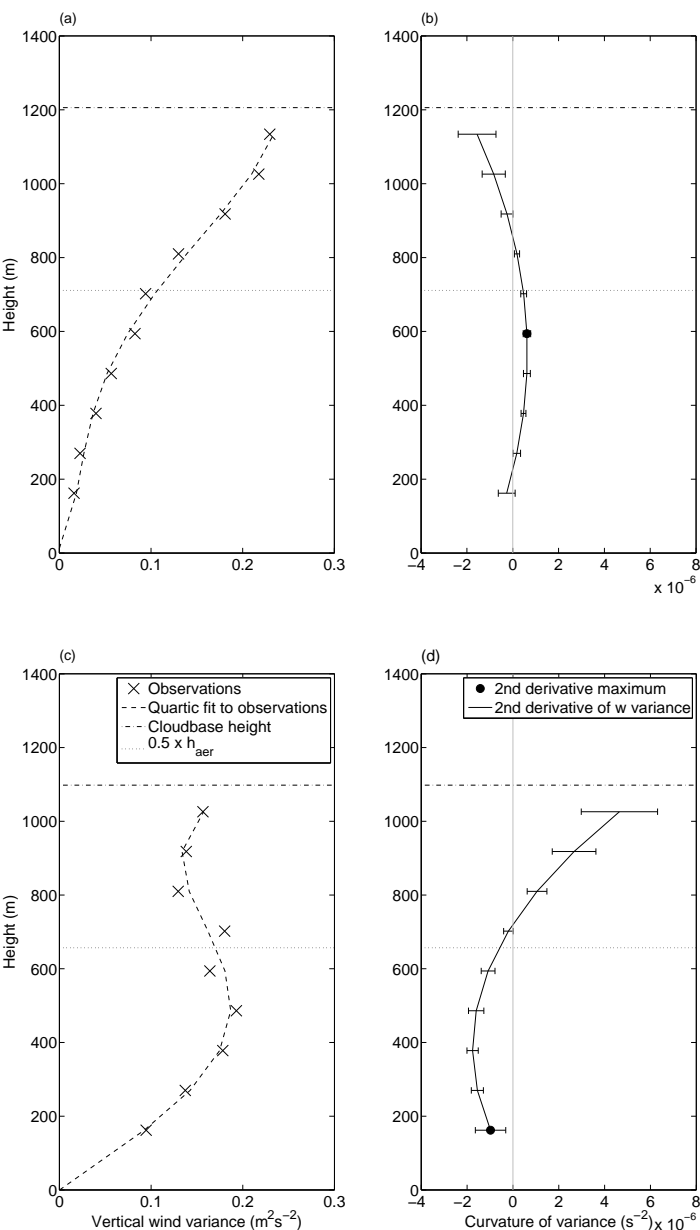

Figure 6. (a) Vertical profile of 2-hourly mean vertical velocity variance observations (crosses) and its corresponding quartic fit(dashed line) for a decoupled boundary layer at 0900 UTC on 18 October 2009. Also shown are the cloud base height (dot-dash line) and the height of the lower half of the boundary layer (dotted line). (b) Vertical profile of the second derivative of the fit of vertical velocity variance and associated error (solid black line). The black circle highlights the height of the maximum curvature of vertical velocity variance in the lower half of the boundary layer which the algorithm uses to assess the probability of the boundary layer being decoupled.(c) As (a) for a coupled boundary layer at 1500 UTC on 18 October 2009.(d) As (b) for a coupled boundary layer.

vertical velocity variance in the lower half of the boundary layer, indicated by a black circle in Figure 6(b) and (d), the error covariance matrix of the coefficients of the quartic fit is used to compute the standard error of the second derivative. As before, the distribution is assumed to be Gaussian and therefore the probability, $p_{\text {de }}$, that the second derivative of the variance is negative in $0<z<h / 2$, can be calculated using the same method as Sections 2.4.2 and 2.4.3, which we equate to the probability the boundary layer is coupled. Where there is insufficient data to perform the quartic fit $p_{\text {de }}$ is set to 0.5 .

\subsubsection{Number of cloud layers present}

Finally, the number of cloud layers present during the hour is estimated directly from the lidar backscatter data. The lidar beam is rapidly attenuated by cloud and therefore we have little information about the depth of the clouds or whether there are multiple cloud layers in a single profile. However, it is possible to use an hour of backscatter profiles from the lidar to determine whether shallow cumulus cloud is present under a stratocumulus layer (types Ic and V). The probability of two or more cloud layers being present in a given hour is estimated by first splitting the hour into three 20 minute windows. The height at which cloud is identified in each lidar profile is found in the first window. These heights are then binned into intervals of $108 \mathrm{~m}, 3$ lidar range gates, and a pdf of these heights is created. Independent cloud layers are identified as peaks in the pdf separated by at least one bin where the probability of cloud is less than 5\%. This threshold is used to ensure that ascending or descending layer clouds (e.g. in the vicinity of fronts) are not diagnosed as multiple layers. The same process is repeated on the remaining two windows (Figure 7). The probability of two or more layers of cloud being present, $p_{2 \text { lay }}$, is the number of 20 -minute windows with two or more layers divided by three, the number of 20minute windows considered. This probability is only used to distinguish between stable boundary-layer types Ib and Ic and unstable types V and VI.

\subsection{Additional constraints}

As with all observational techniques there are limitations in the case of missing data. Firstly, for a boundary-layer type to be diagnosed, we stipulate that more than $90 \%$ of the sonic anemometer and $50 \%$ of the lidar data must be available for each hour. The three lowest lidar range gates are removed as they are unreliable. Therefore the minimum detectable height of the lidar is $108 \mathrm{~m}$. If the aerosol depth is found to be below $270 \mathrm{~m}$ (the 4th range gate) then boundarylayer type is not diagnosed as there are no measurements of below cloud vertical velocity skewness and variance measurements to base the decision on. If the cloud base is diagnosed to be below $270 \mathrm{~m}$ then boundary-layer type is diagnosed as type Ib or IIIb with the probability of each 

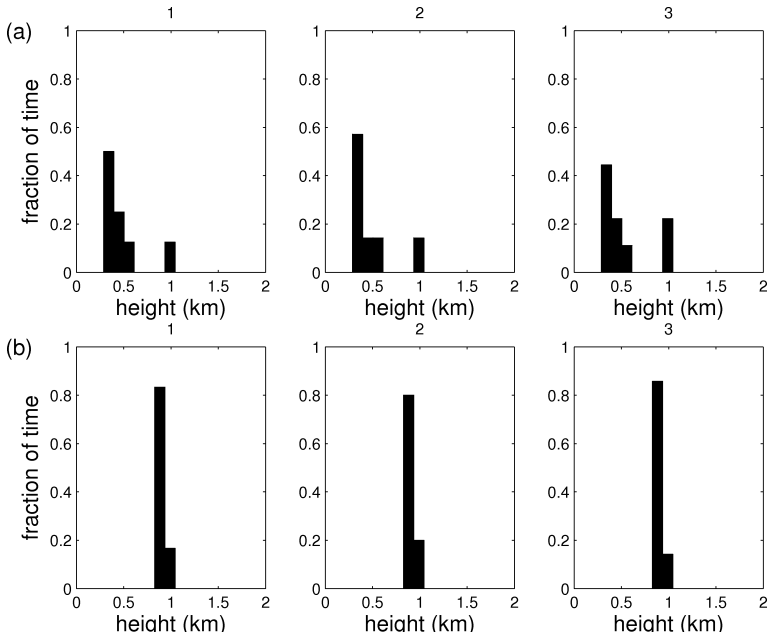

Figure 7. (a) Cloud base height distributions for 1130-1230 UTC on 4 July 2009 (shown in Figure 5) at which time $p_{21 \text { ay }}=1$ (two cloud layers present). (b) Cloud base height distributions for 1430-1530 UTC on 4 July 2009 at which time $p_{2 \text { lay }}=0$ (one cloud layer present). A full description can be found in Section 2.4.5.

Table VIII. The breakdown of the number of hours where boundarylayer type is diagnosed.

\begin{tabular}{lc}
\hline $\begin{array}{l}\text { Number of raining hours } \\
\text { Number of hours with missing }\end{array}$ & 5560 \\
sonic anemometer data & 3663 \\
$\begin{array}{l}\text { Number of hours with missing lidar } \\
\text { data }\end{array}$ & 502 \\
$\begin{array}{l}\text { Number of hours with } h_{\text {aer }} \text { less than } \\
270 \mathrm{~m}\end{array}$ & 159 \\
Number of hours diagnosed & 16396 \\
\hline \hline Total number of hours in dataset & 26280 \\
\hline
\end{tabular}

type being based in the probability of the surface layer being stable. This is imposed as in this situation there is only one lidar gate of information about the vertical velocity skewness and variance to base the decision on. Also, the type is not diagnosed when rain is recorded at Chilbolton. This is due to the lidar retrieval being unreliable when it is raining. Table VIII shows the number of hours each of the above constraints effect in the three year data set considered in this paper $62.38 \%$ of hours are diagnosed. Within the hours that have a boundary-layer type diagnose there are situations that cannot be easily categorised into one of the nine types shown in Figure 1. In these circumstances the most probable boundary-layer type can have a probability as low as $40 \%$.

\section{Results}

The probabilistic algorithm has been applied to 3 years of lidar and sonic anemometer data, 1 June 2008 to 31 May 2011, from Chilbolton. This has been used to produce

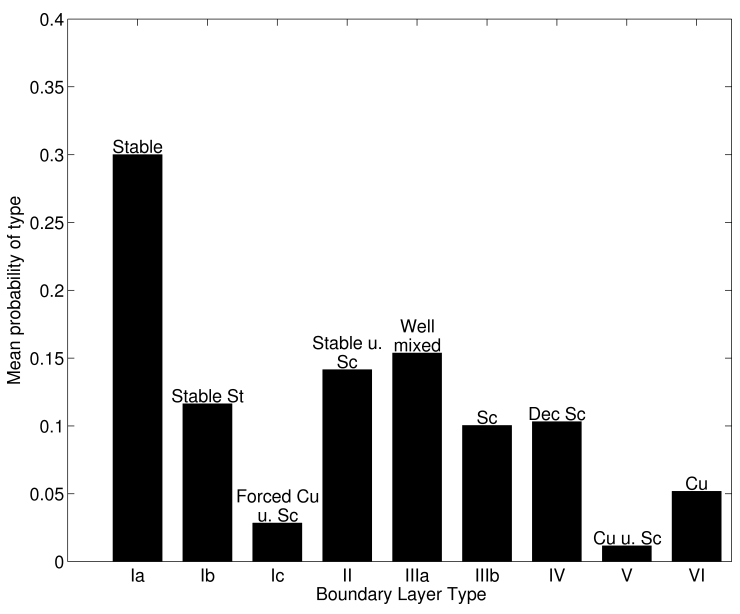

Figure 8. The mean probability of each boundary-layer type over the study period of 1 June 2008 - 31 May 2011.

a long-term statistical analysis of boundary-layer type derived from observations. The distribution of boundarylayer types throughout this period is shown in Figure 8. This distribution is created by summing the probabilities of each type for each hour and then dividing by the total number of hours diagnosed. Overall, it can be seen that the most frequently occurring boundary-layer type is stable with clear skies $(30.0 \%)$. The most frequently occurring unstable type is well mixed with no cloud (15.4\%), followed by decoupled stratocumulus (10.3\%). Cumulus under stratocumulus, little studied over land, occurs during $1.0 \%$ of the period studied. The distribution of types between stable and unstable is similar to that found by Luna and Church (1972) which classifies the boundary layer according to Pasquill stability classes at a single site in Augusta, Georgia. The percentage occurrence of cumulus and stratocumulus cloud is in broad agreement that found over the Southern Great Plains (Lazarus et al. 2000 and Kollias et al. 2007) and all land averaged between 50 and $60^{\circ} \mathrm{N}$ (Hahn et al. 1990).

The observed time series of boundary-layer type can be split both into seasons and time of day. This is shown in Figure 9; note all times are UTC. A clear diurnal and seasonal cycle is present in the boundary-layer types. As expected the boundary layer is nearly always stable in the hours of darkness and in the spring and summer nearly always unstable in daylight thus winter has a much shorter period of unstable boundary-layer types than the summer. This supports the study by Liu and Liang (2010) which 
classified the boundary layer into three regimes, stable, neutral and unstable, using potential temperature profiles from radiosonde ascents from 14 different field campaigns around the world. For the land sites included in their study, they also found a much greater prevalence of unstable convective and neutral boundary layers between 09 UTC and 15 UTC (daylight hours) than during the hours of darkness.

As in the overall distribution the most common type in all seasons is type Ia (stable with no cloud). The occurrence of stable boundary-layer types Ia, Ib, Ic and II is much higher in the winter than the summer. Boundary-layer types $\mathrm{V}$ and VI, those with cumulus cloud, are more prevalent in the warm seasons as are types with stratiform cloud. Cumulus cloud was also found to be most common in warm seasons in the studies by Hahn et al. (1990), Lazarus et al. (2000) and Kollias et al. (2007) however they found that stratiform cloud was more prevalent in the cold seasons which contradicts the increase in the presence of stratiform cloud over the North Atlantic in warm seasons found by Klein and Hartmann (1993). Although the study presented here is over land, not ocean, and so a different cloud climatology might be expected. Cumulus cloud occurrence peaks at midday in the observations presented here. This agrees with Lazarus et al. (2000). Another feature to note is that stratocumulus-topped boundary layers occur more frequently in the afternoon, after 1200 UTC, in all seasons. This finding is also supported by Lazarus et al. (2000). The distribution found using the hourly probabilities is very similar to the distribution of the most common boundarylayer type (not presented here).

\subsection{Most likely sequences of boundary-layer type}

Another feature that can be studied is the most common sequence of boundary-layer type throughout the day. As there are 9 possible types and 24 transitions there are too many possible combinations to consider the whole of the diurnal cycle. By taking the most probable boundary-layer type at five representative times throughout the day it is possible to deduce the most likely evolution of boundarylayer type through the day and whether they concur with the "textbook" evolution of a stable nocturnal boundary layer, with a well mixed convective boundary layer growing after sunrise and cumulus cloud developing as the convective boundary layer grows (Stull 1988 and Garratt 1992). Table IX shows the 20 most common combinations of boundarylayer type, using the most probable type at 0300, 0900, 1200, 1500 and 2100 UTC, along with their frequency of occurrence. Note that only days with boundary layers diagnosed at all these times are included in this analysis. For the period considered here the number of days used is 807.

The most common "day" is that of no cloud with the stability changing from stable to unstable during daylight hours. Even though cloud is common over the UK, this transitional pattern occurs $6.4 \%$ of the time, which equates to 52 days in our 3-year dataset. This pattern being the most probable is not unexpected as there is only one possible sequence for boundary layers that have no cloud (assuming the boundary layer is stable at night and unstable during the day). This low percentage for the most probable sequence implies there is a very large diversity of sequences observed even when using a reduced number of observations. The "textbook" diurnal evolution (Stull 1988) of the boundary layer over land (Stable $\rightarrow$ Well mixed $\rightarrow \mathrm{Cu} \rightarrow \mathrm{Cu}$ $\rightarrow$ Stable) only occurs $0.9 \%$ of the time at Chilbolton, the fifth most probable transition. It is more common to have stratocumulus-capped boundary layers throughout all daylight hours (1.2\%). The top ten boundary-layer transition sequences account for approximately $13.9 \%$ of the period studied. It is surprising to find such a large number of unstable cases during the night. Well mixed cases at 21 UTC (fourth) are related to longer day length in the warm seasons but the well mixed types at 03 UTC (sixth) are due the probability of the surface layer being stable, $p_{s t}$, being small. The top twenty results are largely invariant of whether the start time used is 0200,0300 or 0400 UTC.

The skewness and variance characteristics of boundary-layer types IIIa (well mixed) and VI (cumulus) are similar but with type VI having a cumulus cloud capping the aerosol layer. This similiarity can be seen by comparing Figures 3 and 5. Also, there are several transitions that are similar if the time of the transition from stable to unstable is ignored. An example of this is pattern one and three. Both sequences are cloud free but pattern three comes from winter days where the sensible 

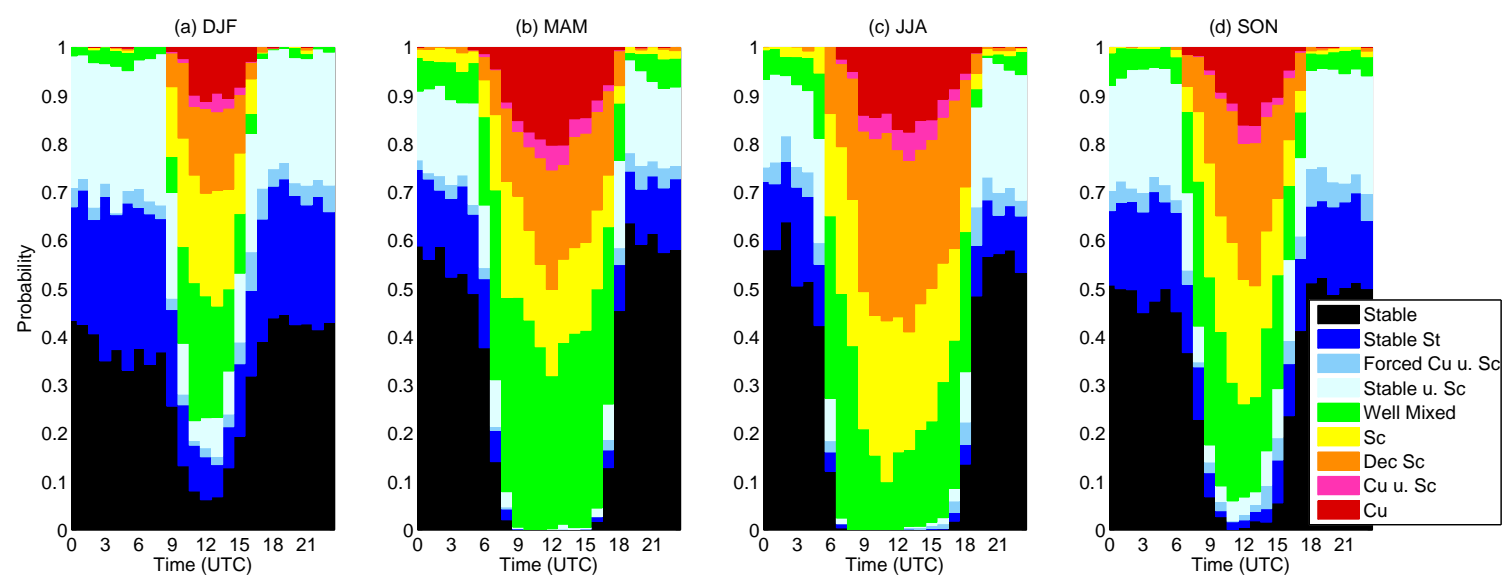

Figure 9. The diurnal distribution of boundary-layer types as a function of season (a) winter, (b) spring, (c) summer, (d) autumn.

Table IX. Most common boundary-layer type evolutions, grey shading indicating the presence of cloud.

\begin{tabular}{|c|c|c|c|c|c|c|}
\hline \multicolumn{5}{|c|}{ Time of Day } & \multicolumn{2}{|c|}{ Occurence } \\
\hline 03:00 & 09:00 & $12: 00$ & $15: 00$ & $21: 00$ & percentage of time & number of days \\
\hline Stable & Well mixed & Well mixed & Well mixed & Stable & 6.4 & 52 \\
\hline Stable St & $\mathrm{Sc}$ & $\mathrm{Sc}$ & $\mathrm{Sc}$ & Stable St & 1.4 & 11 \\
\hline Stable & Stable & Well mixed & Stable & Stable & 1.2 & 10 \\
\hline Stable & Well mixed & Well mixed & Well mixed & Well mixed & 1.0 & 8 \\
\hline Stable & Well mixed & $\mathrm{Cu}$ & $\mathrm{Cu}$ & Stable & 0.9 & 7 \\
\hline Well mixed & Well mixed & Well mixed & Well mixed & Stable & 0.9 & 7 \\
\hline Stable u. Sc & Well mixed & Well mixed & Well mixed & Stable & 0.7 & 6 \\
\hline Stable & $\mathrm{Sc}$ & $\mathrm{Sc}$ & Well mixed & Stable & 0.7 & 6 \\
\hline Stable & Well mixed & Well mixed & Well mixed & Stable u. Sc & 0.7 & 6 \\
\hline Stable u. Sc & $\mathrm{Sc}$ & Dec. Sc & Dec. Sc & Stable & 0.6 & 5 \\
\hline Stable & Sc & Dec. Sc & Dec. Sc & Stable u. Sc & 0.6 & 5 \\
\hline Stable & Well mixed & Well mixed & $\mathrm{Cu}$ & Stable & 0.6 & 5 \\
\hline Stable St & $\mathrm{Sc}$ & $\mathrm{Sc}$ & $\mathrm{Sc}$ & Stable u. Sc & 0.5 & 4 \\
\hline Stable St & Sc & $\mathrm{Sc}$ & Dec. Sc & Stable & 0.5 & 4 \\
\hline Stable St & Sc & Dec. Sc & Dec. Sc & Stable u. Sc & 0.5 & 4 \\
\hline Stable St & Sc & $\mathrm{Cu}$ & Dec. Sc & Stable & 0.5 & 4 \\
\hline Stable St & Sc & $\mathrm{Cu}$ & $\mathrm{Cu}$ & Stable & 0.5 & 4 \\
\hline Stable St & Sc & $\mathrm{Cu}$ & Well mixed & Stable & 0.5 & 4 \\
\hline Stable St & $\mathrm{Sc}$ & Well mixed & Well mixed & Stable & 0.5 & 4 \\
\hline Stable St & Dec. Sc & Dec. Sc & Dec. Sc & Stable & 0.5 & 4 \\
\hline
\end{tabular}

heat flux is negative at 0900 and 1500 UTC but positive at 1200UTC with no cloud. If Table IX is reconsidered with this in mind then transition patterns $1,3,4,5,6,7,9$ and 12 can be combined giving the most common transition occurring $11.5 \%$ of the time. Sequences $2,10,11,13,14$, 15 and 20 can be combined as stratocumulus cloud is present throughout daylight hours $(4.5 \%)$. Also, sequences 5 and 12 can be combined increasing the occurrence of the "textbook" diurnal evolution of the boundary layer to $1.5 \%$ of the time considered.
In this paper it has been demonstrated that it is possible to classify the boundary layer into 9 different types using variables obtained from a continually operating vertically pointing Doppler lidar combined with surface sensible heat flux measurements. The new method has been applied to 3 years of data and a climatology of boundary-layer type has been produced. This climatology exhibits clear diurnal and seasonal cycles which are dominated by variations in the surface sensible heat flux. The most common boundarylayer type is stable with clear skies $(30.0 \%)$. The most common unstable boundary-layer type is unstable cloud 
free $(15.4 \%)$. Decoupled stratocumulus-capped boundary layers which are little studies over land occur $10.3 \%$ of the time. More cumulus capped boundary layers are diagnosed in the warm seasons than in the winter.

The most probable diurnal sequence of boundary-layer type has also been investigated. It has been found that the most probable evolution is that of a cloud free boundary layer $(6.4 \%$ of the period studied) with the "textbook" boundary layer evolution of stable, well mixed, cumuluscapped, stable, occurring approximately $0.9 \%$ of the period studied. The sensitivity of these results to the chosen threshold values, and other limitations of the method are also discussed.

In the future this approach will be used to evaluate the boundary-layer type diagnosed in the Met Office Unified Model. This is feasible as each of the categories in this study map directly on to the six categories used in the “Lock” Scheme ((Lock et al. 2000)). This comparison could also be extended to other operational models or to different geographical locations which have co-located Doppler lidar and surface heat flux measurements.

\section{Acknowledgements}

We would like to thank Adrian Lock, Alan Grant, Stephen Belcher and Peter Jan van Leeuwen for useful discussions. The $1.5 \mu \mathrm{m}$ Doppler Lidar was acquired with NERC grant NE/C513569/1. The sonic anemometer was acquired with NERC grant NE/D005205/1. The instruments at Chilbolton are operated and maintained by the Rutherton Appleton Laboratory.

\section{References}

Albrecht BA, Bretheton CS, Johnson DW, Schubert WH, Frisch AS. 1995. The Atlantic Stratocumulus Transition experiment - ASTEX. Bull. Am. Meteorol. Soc. 76: 889-904.

Barlow JF, Dunbar TM, Nemitz EG, Wood CR, Gallagher MW, Davies F, O'Connor E, Harrison RM. 2011. Boundary layer dynamics over London, UK, as observed using Doppler lidar during REPARTEE-II. Atmos. Chem. Phys 11: 2111-2125.

Clarke RH. 1970. Observational studies in the atmospheric boundary layer. Q. J. R. Meteorol. Soc. 96: 91-114.

Cuxart J, Yague C, Morales G, Terradellas E, Orbe J, Calvo J, Fernandez A, Soler MR, Infante C, Buenestado P, Espinalt A, Joergensen HE, Rees JM, Vila J, Redondo JM, Cantalapiedra IR, Conangla
L. 2000. Stable atmospheric boundary-layer experiment in Spain (SABLES98): A report. Boundary Layer Meterol. 96: 337-370.

Davies F, Middleton DR, Bozier KE. 2007. Urban air pollution modelling and measurements of boundary layer height. Atmospheric Environment 41: 4040-4049.

Davis KJ, Gamage N, Hagelberg CR, Kiemle C, Lenschow DH, Sullivan PP. 2000. An objective method for deriving atmospheric structure from airborne lidar observations. J. Atmos. Oceanic Technol. 17: 1455-1468.

Emeis S, Schafer K, Munkel C. 2008. Surface-based remote sensing of the mixing-layer height - a review. Meterol. Z. 17: 621-630.

Endlich RM, Ludwig F, Uthe E. 1979. An automatic method for determining the mixing depth from lidar observations. Atmospheric Environment 13: 1051-1056.

Flamant C, Pelon J, Flamant PH, Durand P. 1997. Lidar determination of the entrainment zone thickness at the top of the unstable marine atmospheric boundary layer. Boundary Layer Meterol. 83: 247-284.

Garratt JR. 1992. The atmospheric boundary layer. Cambridge University Press: UK.

Hahn C, Warren S, London Jand Chervin R, Jenne R. 1990. Atlas of simultaneous occurence of different cloud types over land. NCAR Technical Note TN-241+STR .

Hennemuth B, Lammert A. 2006. Determination of the atmospheric boundary layer height from radiosonde and lidar backscatter. Boundary Layer Meterol. 120: 181-200.

Hogan RJ, Grant ALM, Illingworth AJ, Pearson GN, O’Connor EJ. 2009. Vertical velocity variance and skewness in clear and cloudtopped boundary layers as revealed by Doppler lidar. $Q$. J. R. Meteorol. Soc 135: 635-643.

Hogan RJ, Munkunda DB, O’Connor EJ, Illingworth AJ. 2004. Estimate of the global distribution of stratiform supercolled liquid water clouds using the LITE lidar. Geophys. Res. Lett. 31: L05 106.

Kaimal J, Finnigan JJ. 1994. Atmospheric boundary layer flows their structure and measurement. Oxford University Press: New York.

Klein SA, Hartmann DL. 1993. The seasonal cycle of low stratiform clouds. J. Climate. 6: 1587-1606.

Kollias P, Tselioudis G, Albrecht BA. 2007. Cloud climatology at the Southern Great Plains and the layer structure, drizzle and atmosperic modes of continental stratus. J. Geophys. Res. 112: D09 116.

Lazarus SM, Krueger SK, Mace GG. 2000. A cloud climatology of the Southern Great Plains ARM CART. J. Climate. 13: 17621 775-403.

LeMone MA. 1990. Some observations of vertical velocity skewness in the convective planetary boundary layer. J. Atmos. Sci. 47: 11631169.

Lenschow DH, Lothon M, Mayor SD, Sullivan PP, Canut G. 2012. A comparison of higher-order vertical velocity moments in the convective boundary layer from lidar with in situ measurements and large-eddy simulation. Boundary Layer Meterol. 143: 107-123.

Lenschow DH, Wyngaard JC, Pennell WT. 1980. Mean-field and second-moment budgets in a baroclinic, convective boundary layer. 
J. Atmos. Sci. 37: 1313-1326.

Liu S, Liang XZ. 2010. Observed diurnal cycle climatology of planetary boundary layer height. J. Climate 23: 5790-5809.

Lock AP, Brown AR, Bush MR, Martin GM, Smith RNB. 2000. A new boundary-layer mixing scheme - 1 . Scheme description and singlecolumn model tests. Mon. Weath. Rev. 128: 3187-3199.

Lothon M, Lenschow DH, Mayor SD. 2009. Doppler lidar measurements of vertical velocity spectra in the convective planetary boundary layer. Boundary Layer Meterol. 132: 205-226.

Luna RE, Church HW. 1972. A comparison of turbulence intestity and stability ratio measurements to Pasquill stability classes. J. Appl. Meteor. 11: 663-669.

Moeng C, Rotunno R. 1990. Vertical-velocity skewness in the bouyancy-driven boundary layer. J. Atmos. Sci. 47: 1149-1162.

Mok TM, Rudowicz CZ. 2004. A lidar study of the atmospheric entrainment zone and mixed layer over Hong Kong. Atmospheric Research 69: 147-163.

Moyer KA, Young GS. 1991. Observations of vertical velocity skewness within the marine stratocumulus-topped boundary layer. J. Atmos. Sci. 48: 403-410.

Newsom RK, Ligon D, Calhoun R, Heap R, Cregan E, Princevac M. 2005. Retrieval of microscale wind and temperature fields from single- and dual-Doppler lidar data. J. Appl. Met. 44: 1324-1345.

Norris JR. 1998. Low cloud type over the ocean from surface observations - 2. geographical and seasonal variations. J. Climate. 11: $383-403$.

Pearson G, Davies F, Collier C. 2008. An analysis of the performace of the UFAM pulsed Doppler lidar for observing the boundary layer. $J$. Atmos. Oceanic Technol. 26: 240-250.

Pearson G, Davies F, Collier C. 2010. Remote sensing of the tropical rain forest boundary layer using pulsed Doppler lidar. Atmos. Chem. Phys. Discuss. 10: 5021-5049.

Poulos GS, Blumen W, Fritts DC, Lundquist JK, Sun J, Burns SP, Nappo C, Banta R, Newsom R, Cuxart J, Terradellas E, Balsley B, Jensen M. 2002. CASES-99: A comprehensive investigation of the stable nocturnal boundary layer. Bull. Am. Meteorol. Soc. 83: 555-581.

Seibert P, Beyrich F, Gryning SE, Joffre S, Rasmussen A, Tercier P. 2000. Review and intercomparison of operational methods for the determiniation of the mixing height. Atmospheric Environment 34: 1001-1027.

Sorbjan Z. 1989. Structure of the atmospheric boundary layer. Prentice Hall: New Jersey.

Spiegel MR, Stephens LJ. 1998. Schaum's outline of theory and problems of statistics. McGraw-Hill: London.

Steyn DG, Baldi M, Hoff RM. 1999. The detection of mixed layer depth and entrainment zone thickness from lidar backscatter profiles. $J$. Atmos. Oceanic Technol. 16: 953-959.

Stull RB. 1988. An introduction to boundary layer meteorology. Kluwer Academic Publishers: The Netherlands.
Tabachnick BG, Fidell LS. 1989. Using multivariate statistics. Harper and Row: New York.

Westbrook CD, Illingworth AJ, O'Connor EJ, Hogan RJ. 2010. Doppler lidar measurements of oriented planar ice crystals falling from supercooled and glaciated layer clouds. Q. J. R. Meteorol. Soc. 136: 260-276.

Wilks DA. 1995. Statistical methods in the atmospheric sciences. Academic Press: London. 